\title{
Determinants of modern contraceptive use among postpartum women in two health facilities in urban Ghana: a cross-sectional study
}

Jonathan Ian Coomson ${ }^{1}$ and Abubakar Manu ${ }^{2^{*}}$

\begin{abstract}
Background: Postpartum contraception is important for spacing and limiting childbirth. Although the use of modern contraception has been shown to reduce maternal and child morbidities and mortalities, postpartum women have one of the highest unmet needs for family planning. Inter-birth intervals less than 24 months have adverse effects on both the mother and the child, yet very limited empirical evidence exist on contraceptive use among postpartum women in Ghana. This study sought to determine the prevalence and determinants of modern contraceptive use among postpartum women in the Tema Metropolis, Ghana.
\end{abstract}

Methods: A facility-based cross-sectional survey was conducted among 320 postpartum women with babies aged between three and 15 months. Participants were recruited from child welfare clinics in two government health facilities in the Tema metropolitan area using a simple random sampling technique. Data were analyzed using STATA version 15. Chi-square and multiple logistic regressions techniques were used to examine associations between postpartum contraceptive use and key independent variables. Statistical significance was set at $p=0.05$. Adjusted odds ratios and their 95\% confidence intervals were used to assess the strength of association.

Results: The prevalence rate of modern contraceptive use among postpartum women was $26.3 \%$. Postpartum contraceptive use was significantly associated with past contraceptive use [AOR $=7.7$ (95\%Cl: 3.4-17.5)]; return of menses $[\mathrm{AOR}=4.3(95 \% \mathrm{Cl}$ : 1.7-11.3)]; resumption of sexual activity [AOR $=4.7(95 \% \mathrm{Cl}: 1.4-15.4)]$; discussion of family planning with male partner $[\mathrm{AOR}=3.1$ (95\%Cl: 1.03-9.2)]; male partners' approval of modern contraception $[A O R=18.1(95 \% \mathrm{Cl}: 6.3-51.6)]$; family planning counselling received during antenatal care $[\mathrm{AOR}=3.5(95 \% \mathrm{Cl}$ : 1.3-9.9)] and knowledge of at least one modern methods of contraception available at the health facility $[\mathrm{AOR}=4.7(95 \% \mathrm{Cl}: 1.9-11.5)]$.

Conclusions: Postpartum contraceptive uptake is low among women in the Tema area. Factors that influence modern contraceptive uptake among postpartum women include past modern contraceptive use, resumption of sexual activity and menstruation, male partner involvement in contraception, family planning counselling during antenatal care and knowledge of the modern methods of contraception available at the health facility. Strengthening family planning education and counselling during antenatal care and using a multi-prong strategy to engage men as partners in family planning will improve postpartum contraceptive uptake.

Keywords: Modern contraceptives, Postpartum, Family planning, Women, Ghana

\footnotetext{
* Correspondence: amanu@ug.edu.gh

${ }^{2}$ Department of Population, Family and Reproductive Health, School of

Public Health, University of Ghana, Accra, Ghana

Full list of author information is available at the end of the article
}

(c) The Author(s). 2019 Open Access This article is distributed under the terms of the Creative Commons Attribution 4.0 International License (http://creativecommons.org/licenses/by/4.0/), which permits unrestricted use, distribution, and reproduction in any medium, provided you give appropriate credit to the original author(s) and the source, provide a link to the Creative Commons license, and indicate if changes were made. The Creative Commons Public Domain Dedication waiver (http://creativecommons.org/publicdomain/zero/1.0/) applies to the data made available in this article, unless otherwise stated. 


\section{Background}

Postpartum contraception is one of the means to prevent rapid repeat pregnancies to ensure good health outcomes in both mother and baby. However, in developing countries, postpartum contraceptive uptake is low [1]. The World Health Organization estimates that about 830 women die daily from complications of pregnancy and childbirth worldwide, and nearly all (99\%) of these maternal deaths occur in developing countries [2]. An overwhelming number of these deaths could be prevented through interventions such as the use of modern contraceptive methods. Evidence shows that an estimated 20\% of obstetric deaths would be prevented if modern contraceptive methods were used [3].

Postpartum women have one of the greatest unmet need for family planning but most often than not, do not receive the services needed in ensuring longer birth intervals and reducing unintended pregnancies [4]. In Sub-Saharan Africa (SSA), the low use of modern contraceptives has led to high rates of unintended pregnancies, unsafe abortions and unplanned births [5]. About two-thirds of women would like to avoid pregnancy in the first year after delivery but are not on any postpartum contraceptive method [6,7]. Evidence shows that nearly $95 \%$ of women who are 0 to 12 months postpartum desire to avoid pregnancy in the next 24 months, but $70 \%$ of them do not use contraception [8]. Short inter-birth intervals, that is, inter-birth intervals less than 24 months, are associated with maternal morbidities such as uterine rupture and uteroplacental bleeding disorders (abruptio placenta and placenta praevia) and infant morbidities such as prematurity, low birth weight and stunting [9]. Research indicates that in developing countries, the death rate of children under 5 years would reduce by $13 \%$ if women waited for at least 24 months after birth before conceiving, while a 25\% decrease would be achieved if the waiting time was at least 36 months [10].

Although knowledge of contraceptives is relatively high among women of reproductive age in Ghana, its use remains low [11]. In Ghana, contraceptive prevalence rate among married women is only $27 \%$ for all methods, and $22 \%$ for modern methods [12]. Some studies have looked at the predictors of contraceptive use by postpartum women in developing countries of which Ghana is included. However, most of these studies used secondary data from the Ghana Demographic and Health Survey (GDHS) in 2008. Published research materials on postpartum contraceptives concerning Ghana are mostly those done on the global or regional scale using secondary data from demographic and health surveys $[1,13,14]$. Recently published research works which used primary data to study the factors that influence postpartum contraceptive use in Ghana are limited. This study, therefore, seeks to estimate the prevalence of postpartum modern contraceptive use and to assess the factors that influence modern contraceptive use among postpartum women in the Tema area of Ghana. In-depth knowledge of the factors that influence the use of postpartum modern contraceptives could be used to plan future educational programs on postpartum contraceptive, thereby reducing the maternal and child morbidities and mortalities associated with short inter-birth intervals. Results of this study could also be used for institutional assessment and implementing reforms at the facility level to increase the uptake of postpartum modern contraceptives.

\section{Methods \\ Study design}

This study employed a facility-based cross-sectional design using the quantitative method with structured questionnaires to obtain data from postpartum women with babies aged between three and 15 months.

\section{Study area, population and period}

The study was conducted from May to June 2018, at the Tema General Hospital (TGH) and the Tema Polyclinic (TP). The facilities, located in the Tema Metropolis, about $30 \mathrm{~km}$ to the East of Accra, are the two main government facilities in the Tema District, both of which are operated under the Ghana Health Service (GHS) and offer various services including reproductive and child health services. The study population was all postpartum women attending the child welfare clinic of TGH and TP.

\section{Sample size determination and sampling procedure}

The sample size was calculated based on Cochran's formula $\mathrm{n} \geq\left[\left(Z_{\frac{\alpha}{2}}\right)^{2} \mathrm{P}(1-\mathrm{P})\right] / \mathrm{d}^{2}$.

[15], with the following assumptions: Prevalence (P) of postpartum modern contraceptive use $=22.6 \%$ [16], margin of error $(d)=5 \%, Z_{\frac{\alpha}{2}}=1.96$ at $95 \%$ confidence interval and a non-response rate of $10 \%$. The total minimum sample size was 300 participants.

Proportion-to-size sampling was done to know the number of participants that was needed from each facility. Based on average monthly attendance at the two child welfare clinics, about $68 \%$ of the participants were recruited from TGH while the remaining 32\% were recruited from TP.

At the facility level, a simple random sampling technique was used in selecting participants in the study. Postpartum women assessing the child welfare clinic of TGH and TP who met the criteria for the study were numbered from one till the last person. Pieces of papers with the corresponding numbers just like the numbering of the women were put in an opaque container, mixed thoroughly and blindly selected by a volunteer midwife. 
Postpartum women who had their numbers selected were then invited to participate in the study for that particular day after informed consent had been sought from them. With the help of four research assistants, a maximum of 25 participants were interviewed per day in TGH whilst that of TP was a maximum of 10 interviews per day.

\section{Inclusion criteria}

1. All women of reproductive age who delivered 3-15 months prior to the study, accessing the child welfare clinic of TGH and TP and who were willing to be participants in the study.

2. For postpartum women who were below 18 years at the time of data collection, written informed consent were sought from their guardian or parent who accompanied them to the hospital. Postpartum mothers below the age of 18 years who came to the health facility without a guardian or parent were excluded from the study.

\section{Exclusion criteria}

1. Postpartum women who had had a hysterectomy (surgical removal of the uterus).

2. Postpartum women who did not speak and understand English, Twi or Ga were excluded from the study due to the language barrier.

3. Postpartum women who were pregnant at the time of accessing the Child Welfare Clinic of TGH and TP.

\section{Measures}

Postpartum modern contraceptive use was the dependent variable; and was measured directly with a yes/no response (yes $=1$ and no $=0$ ). Postpartum women were asked to indicate whether they were currently using a modern contraceptive method.

The independent variables such as the use of modern contraceptives before last delivery, resumption of sexual activity, resumption of menstruation after delivery, discussion of family planning with male partner after delivery of last child, male partner's approval of modern contraceptives, antenatal and postnatal care attendance and whether family planning counselling occurred during these visits were measured directly with yes or no questions where yes $=1$ and no $=0$.

Regarding knowledge of modern contraceptive methods available at the health facility, women were asked a yes/no question on whether they knew the available contraceptive methods being offered at the health facility. Women who responded in the affirmative were asked to name the types of contraceptives being offered at the health facility.
Women who correctly named at least one method were deemed to have knowledge of the available methods at the health facility. Women who said they knew the available methods but could not mention correctly any method as well as those who answered no were assumed to have no knowledge of the contraceptive methods available at the facility.

Knowledge of postpartum modern contraceptive side effects was computed by asking women to list the side effects of modern contraceptives they knew. Women who knew no side effect or correctly listed only one side effect were assumed to have a low knowledge of contraceptive side effects. Participants who correctly listed between two to three side effects were deemed to have moderate knowledge. Postpartum women who knew four or more side effects of modern contraceptives were assumed to have high knowledge of the side effects of modern contraceptives.

Knowledge of postpartum physiology was a created composite variable, where women were asked three yes/ no questions where yes $=1$ and no $=0$. The questions included whether or not a postpartum woman can become pregnant when breastfeeding, can become pregnant when her menses has not returned and whether sexual activity had any effect on the time of the return of her menstrual cycle after delivery. A score of 0 or 1 was deemed as low knowledge, 2 as moderate knowledge and 3 as high knowledge.

\section{Data quality assurance}

Four research assistants were recruited and trained. They were trained to ensure correct interpretation of the questionnaires. Research assistants were also trained on how to protect the confidentiality and privacy of participants. The principal investigator supervised and monitored the activities of the research assistants daily during data collection. Questionnaires were constructed in a lay-man's language so as to make it easily understandable and precise as much as possible after a pre-test was conducted on 30 individuals at both the Lekma Hospital and Polyclinic.

\section{Data processing and analysis}

Data were entered into Microsoft Excel spreadsheet (Microsoft Office 2010) and cleaned to eliminate all irregularities. The data were then exported into STATA version 15, coded and cleaned for analysis. Univariate analysis was carried out using frequencies and percentages to describe the exposure and outcome variables independently. Bivariate analysis using the Pearson's Chi square was carried out to examine associations between postpartum modern contraceptive use and the various independent variables. All the independent variables which were found to be significantly associated with postpartum 
modern contraceptive use were fitted in a multivariate analysis using the binary logistic regression technique to determine predictors of postpartum contraceptive use. Odds ratios and their 95\% confidence intervals were used to assess the strength of association. A $p$-value of 0.05 was used to determine statistical significance.

\section{Results}

\section{Socio-demographic characteristics of respondents}

Table 1 presents socio-demographic characteristics of study participants. The median age of participants was 29 years (IQR: 26-33.5). About half of the respondents 159 (49.7\%) were between the ages of 20-29 years. Participants' age ranged between 17 and 47 years. Majority of the study participants 284 (88.7\%) were married or cohabiting. Only 14 (4.4\%) of respondents had no formal education with a vast majority $280(87.6 \%)$ having at least secondary or vocational education. Nearly a quarter $77(24.1 \%)$ of respondents were unemployed. Almost all women in the study (97.2\%) had partners who had at least primary education.

Table 1 Socio-demographic characteristics of respondents

\begin{tabular}{|c|c|c|}
\hline Characteristics & Frequency $(n=320)$ & Percent \\
\hline \multicolumn{3}{|l|}{ Age of mother } \\
\hline$\leq 19$ & 9 & 2.8 \\
\hline $20-29$ & 159 & 49.7 \\
\hline $30-39$ & 137 & 42.8 \\
\hline $40-49$ & 15 & 4.7 \\
\hline \multicolumn{3}{|l|}{ Marital status } \\
\hline Single/divorced/widowed & 36 & 11.3 \\
\hline Married/cohabiting & 284 & 88.7 \\
\hline \multicolumn{3}{|l|}{ Education of mother } \\
\hline No formal education & 14 & 4.4 \\
\hline Primary & 26 & 8.1 \\
\hline Secondary/vocational & 204 & 63.8 \\
\hline Tertiary & 76 & 23.8 \\
\hline \multicolumn{3}{|l|}{ Occupation of mother } \\
\hline Public salaried worker & 32 & 10.0 \\
\hline Private salaried worker & 66 & 20.6 \\
\hline Trader & 113 & 35.3 \\
\hline Unemployed & 77 & 24.1 \\
\hline Other & 32 & 10.0 \\
\hline \multicolumn{3}{|l|}{ Education of partner } \\
\hline No formal education & 9 & 2.8 \\
\hline Primary & 3 & 0.9 \\
\hline Secondary/vocational & 183 & 57.2 \\
\hline Tertiary & 125 & 39.1 \\
\hline
\end{tabular}

\section{Reproductive health characteristics of respondents}

The median number of pregnancies of respondents was 2.5 (IQR: 2-3). About two out of every five women $(42.8 \%)$ had only one child. Modal age group of the last child of participants was 6-8 months. The median age of the last child was 7 months [5-9]. Almost two thirds (63.7\%) of respondents had the desire to have another child and of those who desired to have another child, about $84 \%$ (171) of them desired to have the next child after 21 months from the time of the study. About two in five (43\%) of participants said the pregnancy which resulted in the birth of their last child was not planned or intended. Majority of participants 315 (98.4) had their last delivery in a health facility. Almost all the women $315(97.5 \%)$ had at least one antenatal visit with nearly half $(46.5 \%)$ meeting the current WHO's recommendation of at least eight antenatal care contacts before delivery [17]. Postnatal care attendance was almost universal 319 (99.7\%) with nine in 10 women (90.9\%) satisfying the WHO's recommendation of at least three visits [18] during the postnatal care period (Table 2).

\section{Postpartum contraceptive prevalence rate}

Modern contraceptive prevalence among the postpartum women was $26.395 \%$ CI: $21.5-31.4 \%$. Majority 177 (55.3\%) of participants had never used any form of modern contraceptive method in their reproductive lives. Of the 143 participants who had used modern contraceptives in the past, a little over two-fifth (42.7\%) obtained information about contraceptive use from health workers. Almost a third (29.8\%) of postpartum women who were using modern contraceptives were using injectables (Fig. 1). Of the 284 (73.7\%) postpartum women who were currently not using any modern method of contraception, more than one-third (36.9\%) reported that fear of the side effects was the main problem for non-use of contraception (Fig. 2).

\section{Predictors of postpartum modern contraceptive use}

Tables 3 and 4 summarize bivariate association between postpartum modern contraceptive use and sociodemographic and reproductive health characteristics respectively. Women's age $(p=0.027)$ was the only sociodemographic characteristic found to be associated with postpartum modern contraceptive use. The use of modern contraceptive in the past $(p<0.001)$, return of menstruation $(p=0.049)$, resumption of sexual activity $(\mathrm{p}<$ $0.001)$ and discussion of family planning among spouses $(p<0.001)$ were significantly associated with current modern contraceptive use postpartum women. Other variables significantly associated with modern contraceptive use were male partner approval of modern contraception $(p<0.001)$, whether family planning counselling was received during antenatal care $(p=0.008)$, family 
Table 2 Reproductive health characteristics of participants

\begin{tabular}{ll}
\hline Variable & Number of past pregnancies \\
1 & 6 \\
2 & 96 \\
3 & 88 \\
4 & 5 \\
More than 4 & 18
\end{tabular}

Number of children

$\begin{array}{ll}1 & 137 \\ 2 & 101 \\ 4 & 5 \\ \text { More than } 4 & 26 \\ \text { Age of child } & 6\end{array}$

Age of child
$3-5$ months
6-8 months
9-11 months
12-15 months

Desires to have another child

No
Yes
Within 21 months
After 21 months

Ever used modern contraceptive

$\begin{array}{ll}\text { No } & 177 \\ \text { Yes } & 143\end{array}$

Last pregnancy planned/intended

$\begin{array}{ll}\text { No } & 138 \\ \text { Yes } & 183\end{array}$

Menstruated after delivery

$\begin{array}{ll}\text { No } & 124 \\ \text { Yes } & 196\end{array}$

Resumed sexual activity

$\begin{array}{ll}\text { No } & 110 \\ \text { Yes } & 210\end{array}$

Current modern contraceptive use

$\begin{array}{ll}\text { No } & 236 \\ \text { Yes } & 84\end{array}$

Discussed family planning with partner

$\begin{array}{ll}\text { No } & 156 \\ \text { Yes } & 164\end{array}$

Partners' approval of modern contraception

$\begin{array}{ll}\text { No } & 101 \\ \text { Yes } & 111\end{array}$

42.8

31.6

$$
15.6
$$$$
8.1
$$$$
1.9
$$

30.6

34.7

23.4

11.3

36.3

$V=204$

33

143

164

Percent

$\begin{array}{ll}\text { Frequency }(n=320) & \text { Percent } \\ 64 & \\ 96 & 20.0 \\ 88 & 30.0 \\ 54 & 27.5 \\ 18 & 16.8 \\ & 5.7\end{array}$

Table 2 Reproductive health characteristics of participants (Continued)

\begin{tabular}{|c|c|c|}
\hline Variable & Frequency $(n=320)$ & Percent \\
\hline I do not know & 108 & 33.7 \\
\hline \multicolumn{3}{|l|}{ Place of delivery } \\
\hline Health facility & 315 & 98.4 \\
\hline home & 5 & 1.6 \\
\hline \multicolumn{3}{|l|}{ Antenatal attendance } \\
\hline No & 8 & 2.5 \\
\hline Yes & 312 & 97.5 \\
\hline Number of antenatal attendance & $N=312$ & \\
\hline Less than 8 visits & 167 & 53.5 \\
\hline 8 or more visits & 145 & 46.5 \\
\hline FP counselling at antenatal & $N=312$ & \\
\hline No & 80 & 25.6 \\
\hline Yes & 232 & 74.4 \\
\hline \multicolumn{3}{|l|}{ Postnatal attendance } \\
\hline No & 1 & 0.3 \\
\hline Yes & 319 & 99.7 \\
\hline Number of postnatal attendance & $N=319$ & \\
\hline Less than 3 visits & 29 & 9.1 \\
\hline 3 or more visits & 290 & 90.9 \\
\hline FP counselling at postnatal & $N=319$ & \\
\hline No & 200 & 62.7 \\
\hline Yes & 119 & 37.3 \\
\hline \multicolumn{3}{|l|}{ Knowledge of side effects } \\
\hline Low knowledge & 108 & 33.8 \\
\hline Moderate knowledge & 155 & 48.4 \\
\hline High knowledge & 57 & 17.8 \\
\hline \multicolumn{3}{|c|}{ Knowledge of postpartum physiology } \\
\hline Low knowledge & 54 & 16.9 \\
\hline Moderate knowledge & 131 & 41 \\
\hline High knowledge & 135 & 42.1 \\
\hline \multicolumn{3}{|c|}{ Knowledge of FP methods available at health facility } \\
\hline No & 184 & 57.5 \\
\hline Yes & 136 & 42.5 \\
\hline
\end{tabular}

planning counselling at postnatal care $(\mathrm{p}<0.001)$ and knowing at least one modern contraceptive methods available at the health facility $(\mathrm{p}<0.001)$.

\section{Multivariate logistic regression}

Table 5 presents results of multiple logistic regression of postpartum contraceptive use and selected independent variables. Postpartum women who had ever used a modern contraceptive were 7.7 times likely to be currently using a modern contraceptive compared to those who 


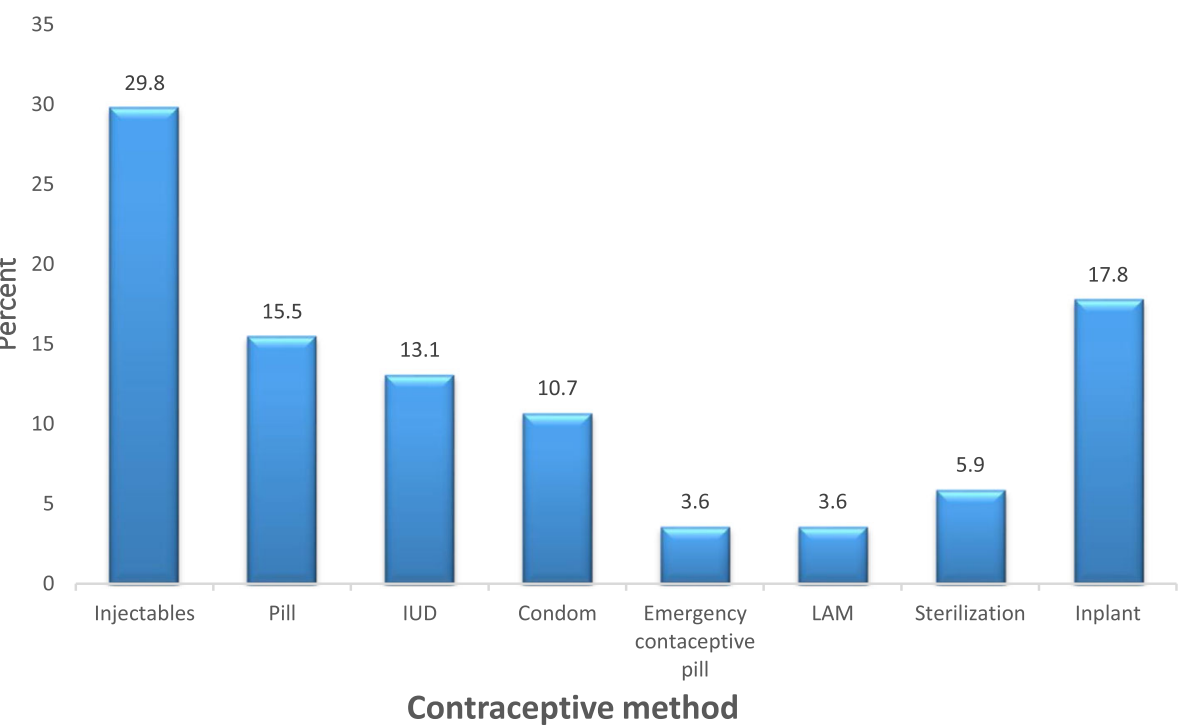

Fig. 1 Preferred methods of postpartum modern contraception

had never used a modern contraceptive method [AOR = 7.7 (95\% CI: 3.4-17.5)]. Postpartum women whose menses had returned compared to those who were yet to have a return of menstrual flow were 4.3 times likely to be using a modern contraceptive method $[\mathrm{AOR}=4.3$ (95\% CI: 1.7-11.3)]. Likewise, women who have resumed sexual activity have 4.7 times increased odds of using a modern method of contraception compared to those who are yet to resume sexual activity after delivery $[\mathrm{AOR}=4.7$ (95\% CI: 1.4-15.4)]. Spouses who have discussed family planning have $310 \%$ increased odds of using a postpartum modern contraceptive compared to spouses who have not had any discussion on family planning $[\mathrm{AOR}=3.1 \quad(95 \% \mathrm{CI}$ : 1.03-9.2)]. There was an 18.1 higher odds of using modern contraceptives among postpartum women whose partners' approved of the use of modern contraceptives compared to women whose partners' did not $\quad[\mathrm{AOR}=18.1 \quad(95 \%$ CI: $6.3-51.6)]$. Postpartum women who received family planning counselling during antenatal care visits at health facilities were 3.5 times likely to be on modern contraceptives during the study than those who said they received no family planning counselling during antenatal care $[\mathrm{AOR}=3.5$ (95\% CI: 1.3-9.9)]. Lastly, postpartum women who knew at least a modern contraceptive method

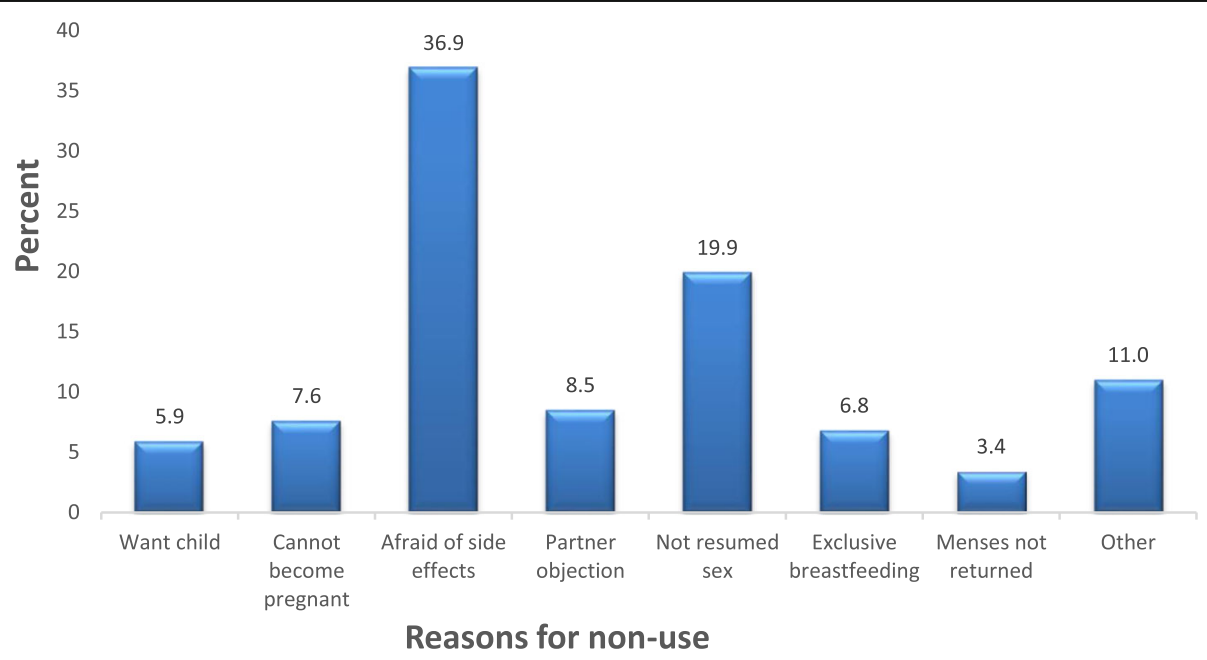

Fig. 2 Reasons for non-use of postpartum modern contraception 
Table 3 Bivariate analysis of socio-demographic characteristics associated with current postpartum modern contraceptive use

\begin{tabular}{|c|c|c|c|c|}
\hline \multirow[t]{2}{*}{ Characteristic } & \multicolumn{2}{|c|}{ Contraceptive use, n (\%) } & \multirow{2}{*}{$\begin{array}{l}\text { Chi } \\
\text { square }\end{array}$} & \multirow{2}{*}{$\begin{array}{l}\text { P- } \\
\text { value }\end{array}$} \\
\hline & No & Yes & & \\
\hline \multicolumn{5}{|l|}{ Age of mother } \\
\hline $10-19$ & $7(3.0)$ & $2(2.4)$ & \multirow[t]{4}{*}{9.20} & \multirow[t]{4}{*}{0.027} \\
\hline $20-29$ & $126(53.4)$ & $33(39.3)$ & & \\
\hline $30-39$ & $96(40.6)$ & $41(48.8)$ & & \\
\hline $40-49$ & $7(3.0)$ & $8(9.5)$ & & \\
\hline \multicolumn{5}{|l|}{ Marital status } \\
\hline Single/widow/divorced & $24(10.2)$ & $12(14.3)$ & \multirow[t]{2}{*}{1.05} & \multirow[t]{2}{*}{0.305} \\
\hline Married/cohabiting & $212(89.8)$ & $72(85.7)$ & & \\
\hline \multicolumn{5}{|l|}{ Education of mother } \\
\hline No formal education & $10(4.3)$ & $4(4.8)$ & & \multirow[t]{4}{*}{$0.298^{*}$} \\
\hline Primary & $22(9.3)$ & $4(4.8)$ & & \\
\hline Secondary/vocational & $144(61.0)$ & $60(71.4)$ & & \\
\hline Tertiary & $60(25.4)$ & $16(19.0)$ & & \\
\hline \multicolumn{5}{|l|}{ Occupation of mother } \\
\hline Unemployed & $59(25.0)$ & $18(21.4)$ & \multirow[t]{2}{*}{0.43} & \multirow[t]{2}{*}{0.511} \\
\hline Employed & $177(75.0)$ & $66(78.6)$ & & \\
\hline \multicolumn{5}{|l|}{ Education of partner } \\
\hline No formal education & $8(3.4)$ & $1(1.2)$ & & \multirow[t]{4}{*}{$0.349^{*}$} \\
\hline Primary & $2(0.9)$ & $1(1.2)$ & & \\
\hline Secondary/vocational & $129(54.6)$ & $54(64.3)$ & & \\
\hline Tertiary & $97(41.1)$ & $28(33.3)$ & & \\
\hline
\end{tabular}

*Fisher's exact

available at the health facility (Tema General Hospital and Tema Polyclinic) were 4.7 times likely to be currently using a modern method of contraception than women who had no idea of the contraceptive methods available at the health facility $[\mathrm{AOR}=4.7$ (95\% CI: 1.9-11.5)].

\section{Discussion}

This study sought to find the prevalence of modern contraceptive methods among postpartum women attending the child welfare clinic of Tema General Hospital and Tema polyclinic as well as assess the determinants of modern contraceptive use. Determinants of modern contraceptive uptake among postpartum women include past modern contraceptive use, resumption of sexual activity and menstruation, male partner involvement in contraception, family planning counselling during antenatal care and knowledge of the modern methods of contraception available at the health facility.

The prevalence of postpartum modern contraceptive use was $26.3 \%$ with the $95 \%$ confidence interval of 21.5 to $31.4 \%$. This finding is in line with the modern contraceptive prevalence rate of $22 \%$ found during the GDHS of 2014 [12]. The low prevalence of modern contraceptive use among postpartum women in this study could result in rapid repeat pregnancies with the resultant short inter-birth interval, which have been shown by several studies [19-24] to be detrimental to the health of both the mother and the child. Past modern contraceptive use, return of menstrual cycle, resumption of sexual activity, discussion of family planning with male partner and male partners' approval of contraceptives were found to be associated with postpartum modern contraceptive use. Other factors significantly associated with modern contraceptive use among postpartum women were family planning counselling during antenatal care and knowledge of at least one modern contraceptive method available at the health facility.

The most preferred method of contraception was injectables (29.8\%) which was consistent with several studies around the world [1, 12, 25-27]. All these studies showed a preference of women for short acting hormonal contraceptive methods such as injectables and the pill. However, long acting reversible methods such as IUDs and implants as well as permanent methods are known to be more effective in pregnancy prevention [28]. In this study, the commonest reason given by women for not being on any modern contraceptive method was the fear of side effects (36.9\%). Non-use of modern contraceptive methods due to health concerns and fear of side effects are also common reasons given by women in Africa and other parts of the world [12, 14, 29].

Past modern contraceptive use prior to the last pregnancy increased the likelihood of current modern contraceptive use among postpartum women. This association is also seen in other studies across the world [30, 31]. This relationship may be due to the fact that women recognize the benefits of modern contraceptive use after initial use and continue to use them later on in life. Perhaps, they realize that the myths and side effects of contraceptives are over-exaggerated when they use it themselves and continue to use them in the postpartum period to space and limit childbirth.

Additionally, women whose menstrual cycle had returned after delivery were more likely to use modern contraception. This findings is in consonance with existing evidence indicating that most women prefer to use contraception when they had resumed menstruation [25, 32]. A survey of 17 low and middle income countries [33] using secondary data from their demographic and health surveys revealed a trend of postpartum women waiting for the return of their menses before the uptake of a modern method of contraception. The public health implication of this finding is that it can lead to a rise 
Table 4 Bivariate analysis of other factors associated with postpartum modern contraceptive use

\begin{tabular}{|c|c|c|}
\hline Characteristic & Contraceptive use, n (\%) & Chi square $p$-value \\
\hline & Yes & \\
\hline
\end{tabular}

Number of past pregnancies

$\begin{array}{lllll}1 & 53(22.5) & 11(13.1) & 7.87 & 0.096 \\ 2 & 75(31.8) & 21(25.0) & \\ 3 & 62(26.3) & 26(31.0) & \\ 4 & 35(14.8) & 19(22.6) & \\ \text { More than 4 } & 11(4.6) & 7(8.3) & \end{array}$

Number of children

\begin{tabular}{|c|c|c|}
\hline 1 & $107(45.3)$ & $30(35.7)$ \\
\hline 2 & $72(30.5)$ & $29(34.5)$ \\
\hline 3 & 38 (16.1) & $12(14.3)$ \\
\hline 4 & $14(5.9)$ & $12(14.3)$ \\
\hline More than 4 & $5(2.2)$ & $1(1.2)$ \\
\hline
\end{tabular}

Age of child

$\begin{array}{llll}\text { 3-5 months } & 76(32.2) & 22(26.2) & 2.04 \\ 6-8 \text { months } & 82(34.8) & 29(34.5) & \\ 9-11 \text { months } & 51(21.6) & 24(28.6) & \\ 12-15 \text { months } & 27(11.4) & 9(10.7) & \end{array}$

Desires another child

$\begin{array}{llll}\text { No } & 84(14.5) & 32(21.2) & 0.17 \\ \text { Yes } & 152(85.5) & 52(78.8) & \end{array}$

When next child is desired

$\begin{array}{llll}\text { Within } 21 \text { months } & 22(66.7) & 11(33.3) & 1.28 \\ \text { After } 21 \text { months } & 130(76.0) & 41(24.0) & \end{array}$

Ever used modern contraceptive

$\begin{array}{lllll}\text { No } & 154(65.3) & 23(27.4) & 35.95 & <0.001 \\ \text { Yes } & 82(34.7) & 61(72.6) & & \end{array}$

Last pregnancy planned/intended

$\begin{array}{llll}\text { No } & 101(42.8) & 37(44.0) & 0.04 \\ \text { Yes } & 135(57.2) & 47(56.0) & \end{array}$

Menses returned

$\begin{array}{lllll}\text { No } & 99(42.0) & 25(29.8) & 3.88 & 0.049 \\ \text { Yes } & 137(58.0) & 59(70.2) & & \\ \text { Resumed sexual activity } & & & & \\ \text { No } & 103(43.6) & 7(8.3) & 34.24 & <0.001 \\ \text { Yes } & 133(56.4) & 77(91.7) & & \end{array}$

Discussed FP with partner

$\begin{array}{lllll}\text { No } & 144(61.0) & 12(14.3) & 54.15 & <0.001 \\ \text { Yes } & 92(39.0) & 72(85.7) & & \end{array}$

Partner approves modern contraception

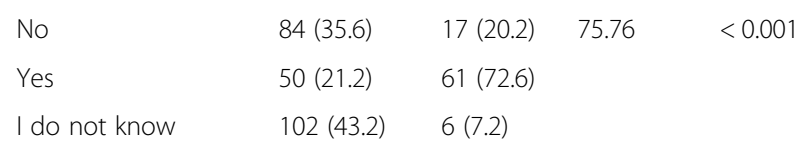

Table 4 Bivariate analysis of other factors associated with postpartum modern contraceptive use (Continued)

\begin{tabular}{|c|c|c|c|c|}
\hline \multirow[t]{2}{*}{ Characteristic } & \multicolumn{2}{|c|}{ Contraceptive use, n (\%) } & \multirow[t]{2}{*}{ Chi square } & \multirow[t]{2}{*}{$p$-value } \\
\hline & No & Yes & & \\
\hline \multicolumn{5}{|l|}{ Place of delivery } \\
\hline Health facility & $232(98.3)$ & $83(98.8)$ & & $1.000^{*}$ \\
\hline home & $4(1.7)$ & $1(1.2)$ & & \\
\hline \multicolumn{5}{|l|}{ ANC attendance } \\
\hline No & $6(2.5)$ & $2(2.4)$ & & $1.000^{*}$ \\
\hline yes & $230(97.5)$ & $82(97.6)$ & & \\
\hline \multicolumn{5}{|l|}{ FP counselling at antenatal } \\
\hline No & $68(29.6)$ & $12(14.6)$ & 7.068 & 0.008 \\
\hline Yes & $162(70.4)$ & $70(85.4)$ & & \\
\hline \multicolumn{5}{|l|}{ PNC attendance } \\
\hline No & $0(0.0)$ & $1(1.2)$ & & $0.262^{*}$ \\
\hline Yes & $236(100.0)$ & $83(98.8)$ & & \\
\hline \multicolumn{5}{|l|}{ FP counselling at PNC } \\
\hline No & $166(70.3)$ & $34(41.0)$ & 22.66 & $<0.001$ \\
\hline Yes & $70(29.7)$ & $49(59.0)$ & & \\
\hline \multicolumn{5}{|l|}{ Knowledge of side effects } \\
\hline Low knowledge & $75(31.8)$ & $33(39.3)$ & 3.84 & 0.147 \\
\hline Moderate knowledge & $122(51.7)$ & $33(39.3)$ & & \\
\hline High knowledge & $39(16.5)$ & $18(21.4)$ & & \\
\hline \multicolumn{5}{|c|}{ Knowledge of postpartum physiology } \\
\hline Low knowledge & $41(17.4)$ & $13(15.5)$ & 1.42 & 0.491 \\
\hline Moderate knowledge & $92(39.0)$ & $39(46.4)$ & & \\
\hline High knowledge & $103(43.6)$ & $32(38.1)$ & & \\
\hline \multicolumn{5}{|c|}{ Knowledge of available FP methods } \\
\hline No & $163(69.1)$ & $21(25.0)$ & 49.23 & $<0.001$ \\
\hline Yes & $73(30.9)$ & $63(75.0)$ & & \\
\hline
\end{tabular}

*Fishers' exact

in unplanned and unintended pregnancies because women mistakenly think postpartum amenorrhoea means they cannot become pregnant. Pregnancy is possible in postpartum women because ovulation, which is the releases of eggs by the ovary can occur before menstruation $[34,35]$.

As expected, women who had resumed sexual activity after delivery were more likely to use modern contraception. This finding is consistent with two studies from East Africa that found that resumption of sex predicts modern contraceptive use among postpartum women [32, 36].

It was also evident that family planning discussion among couples after last delivery increases postpartum contraceptive uptake. Hameed et al. [37] demonstrated in the Punjab Province of Pakistan, that when couples jointly make the decision to use contraceptives, its use was significant than 
Table 5 Logistic regression analysis of factors influencing postpartum modern contraceptive use

\begin{tabular}{|c|c|c|c|c|}
\hline Variable & $\operatorname{COR}(95 \% \mathrm{Cl})$ & $p$-value & AOR $(95 \% \mathrm{Cl})$ & p-value \\
\hline \multicolumn{5}{|l|}{ Age of mother } \\
\hline $10-19$ & Ref & & Ref & \\
\hline $20-29$ & $0.9(0.2-4.6)$ & 0.916 & $1.5(0.2-9.3$ & 0.683 \\
\hline $30-39$ & $1.5(0.3-7.5)$ & 0.625 & $1.6(0.3-10.5)$ & 0.610 \\
\hline $40-49$ & $4.0(0.6-26.0)$ & 0.146 & $2.4(0.2-30.7)$ & 0.490 \\
\hline \multicolumn{5}{|c|}{ Ever used modern contraceptive } \\
\hline No & Ref & & Ref & $<0.001$ \\
\hline Yes & $5.0(2.9-8.6)$ & $<0.001$ & $7.7(3.4-17.5)$ & \\
\hline Menstruated after delivery & & & & 0.003 \\
\hline No & Ref & & Ref & \\
\hline Yes & $1.7(1.0-2.9)$ & 0.050 & $4.3(1.7-11.3)$ & \\
\hline Resumed sexual activity & & & & 0.011 \\
\hline No & Ref & & Ref & \\
\hline Yes & $8.5(3.7-19.3)$ & $<0.001$ & $4.7(1.4-15.4)$ & \\
\hline \multicolumn{5}{|c|}{ Discussed family planning with partner } \\
\hline No & Ref & & Ref & 0.044 \\
\hline Yes & $9.4(4.8-18.3)$ & $<0.001$ & $3.1(1.03-9.2)$ & \\
\hline \multicolumn{5}{|c|}{ Partners' approval of modern contraceptive use } \\
\hline No & Ref & & Ref & \\
\hline Yes & $6.0(3.2-11.4)$ & $<0.001$ & $18.1(6.3-51.6)$ & $<0.001$ \\
\hline I do not know & $0.3(0.1-0.8)$ & 0.013 & $7.7(1.6-38.1)$ & 0.012 \\
\hline \multicolumn{5}{|c|}{ Family planning counselling at antenatal } \\
\hline No & Ref & & Ref & \\
\hline Yes & $2.4(1.2-4.8)$ & 0.009 & $3.5(1.3-9.9)$ & 0.016 \\
\hline \multicolumn{5}{|c|}{ Family planning counselling at postnatal } \\
\hline No & Ref & & Ref & 0.139 \\
\hline Yes & $3.4(2.0-5.7)$ & $<0.001$ & $2.0(0.8-5.3)$ & \\
\hline \multicolumn{5}{|c|}{ Knowledge of available family planning methods at the health facility } \\
\hline No & ref & & Ref & 0.001 \\
\hline Yes & $6.7(3.8-11.8)$ & $<0.001$ & $4.7(1.9-11.5)$ & \\
\hline
\end{tabular}

when the decision was made to use it only by the woman. This goes a long way to show the importance of involving the male partner in decisions regarding contraception. Likewise, male partners' approval of modern contraceptives increases its use. This association is not surprising because in many parts of the world especially SSA, husbands are the heads of families and major decisions such as fertility desires has to be approved by them.

Postpartum modern contraceptive use was significantly associated with family planning counselling during antenatal care as seen in several studies across the world [1, 30, 32, 38-41]. Appropriate family planning information and counselling at antenatal care visit allows women enough time to decide which method will be suitable for them in the postpartum period. Family planning counselling during antenatal care may motivate women who were otherwise indecisive to use modern contraceptive methods during the postpartum period.

Knowledge of at least one method of modern contraception available at the health facility increased modern contraceptive use by postpartum women. This relationship may be explained by the fact that in Ghana, health facilities are the major sources of some contraceptive methods [12] and therefore one is expected to know the available methods at the facility before choosing a suitable method.

The study is one of the few in the Tema area that seeks to determine the predictors of modern contraceptive use among postpartum women, thereby adding to the body of knowledge on postpartum contraception. Another strength of this study is that reliable data and appropriate methods were used, thereby ensuring that 
the findings reflect accurately on modern contraceptive use among postpartum women in the Tema area. A limitation of the study is in its design. The cross sectional study design made it impossible to establish causal relationships. Therefore, associations were the best ways to interpret results. Another limitation of the study was recall bias. Postpartum women had to recall certain reproductive health characteristics and behaviours that occurred in the past. Some of these behaviours were selfreported and there was practically no way to independently verify them. Sexual activity and contraceptive use are considered intimate issues in Ghana. This has a potential to lead to some reluctance in answering questions which bordered on those issues. However, this concern was addressed when the confidentiality and privacy of women were respected in the study. Again, this was a facility-based study in an urban setting, and therefore results can only be generalizable to similar urban settings.

\section{Conclusions}

Postpartum modern contraceptive uptake is low among women in the Tema area. Injectables are the most preferred method of modern contraception while the fear of side effects is the major reason for modern contraceptive non-use. Modern contraceptive uptake among postpartum women in the Tema area is influenced by past modern contraceptive use, resumption of sexual activity and menstrual cycle after last delivery, the male partner's involvement in contraception, family planning counselling given by health care providers during antenatal care and postpartum women knowing at least one methods of modern contraception available at the health facility.

There should be an increased advocacy by the Tema Metropolitan Health Directorate to engage men as partners in family planning educational programs since their influence is huge in modern contraceptive uptake among postpartum women. Efforts should be made at the facility level by authorities and health managers to strengthen family planning counselling during antenatal care.

\section{Abbreviations \\ AOR: Adjusted Odds Ratio; Cl: Confidence Interval; COR: Crude Odds Ratio; GDHS: Ghana Demographic and Health Survey; GHS: Ghana Health Service; IQR: Interquartile Range; SSA: Sub-Saharan Africa; TGH: Tema General Hospital; TP: Tema Polyclinic; WHO: World Health Organization.}

\section{Acknowledgements}

We wish to thank all postpartum women at the two health facilities, who spent their valuable time in answering questions during data collection. We also acknowledge our four research assistants, who worked diligently during the data collection process. Our sincere gratitude also goes to the management and staff of the two health facilities, who supported this study in diverse ways.

\section{Authors' contributions}

JIC and AM conceptualized and designed the study. JIC was responsible for study implementation and acquisition of data, conducted data analysis and interpretation, and drafted the initial version of the manuscript. AM contributed to data interpretation, reviewed and revised the manuscript critically for important intellectual content. Both authors read and approved the final manuscript.

Funding

This study was self-financed.

\section{Availability of data and materials}

The dataset that supports the conclusions of this study is included in the article.

\section{Ethics approval and consent to participate}

Ethical clearance was obtained from the Ghana Health Service Ethics Review Committee in Accra (Reference No.GHSERC037/01/18). Permission to carry out the study was granted by the Greater Accra Regional Health Directorate as well as the Tema Metropolitan Health Directorate, the management of both the Tema General Hospital and Tema Polyclinic. Written informed consent was sought from all postpartum women who participated in the study.

\section{Consent for publication}

Consent for publication was sought from all participants of the study.

\section{Competing interests}

The authors declare that they have no competing interests.

\section{Author details}

13M\&C Health System, LG DTD 10081, East Legon, Accra, Ghana.

${ }^{2}$ Department of Population, Family and Reproductive Health, School of

Public Health, University of Ghana, Accra, Ghana.

Received: 31 May 2019 Accepted: 5 September 2019

Published online: 21 October 2019

\section{References}

1. Moore Z, Pfitzer A, Gubin R, Charurat E, Elliott L, Croft T. Missed opportunities for family planning: an analysis of pregnancy risk and contraceptive method use among postpartum women in 21 low- and middle-income countries. Contraception. 2015;92(1):31-9. https://doi.org/10. 1016/j.contraception.2015.03.007.

2. Blencowe H, Cousens S, Jassir FB, Say L, Chou D, Mathers C, et al. National, regional, and worldwide estimates of stillbirth rates in 2015, with trends from 2000: a systematic analysis. Lancet Glob Heal. 2016;4(2):e98-108 Available from: http://linkinghub.elsevier.com/retrieve/pii/S2214109X15002 752. [cited 2017 Oct 14].

3. Collumbien M, Gerressu M, Cleland J. Non-use and use of ineffective methods of contraception. In: Ezzati M, Lopez A, Anthony R, Murray C, editors. Comparative quantification of health risks; 2004. p. 1255-320. Available from: http://researchonline.Ishtm.ac.uk/id/eprint/17866.

4. Winikoff B, Mensch B. Rethinking postpartum family planning. Stud Fam Plan. 2015;22(5):294-307.

5. Apanga PA, Adam MA. Factors influencing the uptake of family planning services in the Talensi district, Ghana. Pan Afr Med J. 2015:20:1-9.

6. Ross JA, Winfrey WL. Contraceptive use, intention to use and unmet need during the extended postpartum period. Int Fam Plan Perspect. 2001;27(1): 20 Available from: http://www.jstor.org/stable/2673801?origin=crossref.

7. Rossier C, Bradley SEK, Ross J, Winfrey W. Reassessing unmet need for family planning in the postpartum period. Stud Fam Plan. 2015;46(4):355-67.

8. $\mathrm{WHO} \mid$ Postpartum family planning, editor. essential for ensuring health of women and their babies. World Health Organisation: World Health Organization; 2018. Available from: https://www.who.int/reproductivehealth/ topics/family_planning/world-contraception-day-2018/en/. [cited 2019 May 25]

9. Conde-Agudelo A, Rosas-Bermúdez A, Castano F, Horton MH. Effects of birth spacing on maternal, perinatal, infant, and child health: a systematic review of causal mechanisms. Stud Fam Plan. 2012:43(2):93-114.

10. Rutstein SO. Effects of preceding birth intervals on neonatal, infant and under-five years mortality and nutritional status in developing countries: evidence from the demographic and health surveys. Int J Gynecol Obstet. 2005:89(Suppl 1):S7-S24.

11. Opoku B. Contraceptive Preferences of Post-Abortion Patients in Ghana. J Women's Heal Care. 2012;01(02) Available from: https://www.omicsgroup. org/journals/2167-0420/2167-0420-1-109.digital/2167-0420-1-109.html. 
12. Ghana Statistical Service, Ghana Health Service, ICF Macro International. Ghana Demographic and Health Survey 2015;

13. Tsui AO, Brown W, Li Q. Contraceptive practice in sub Saharan Africa. HHS Public Access. 2017:43:166-91.

14. Sedgh G, Hussain R. Reasons for Contraceptive Nonuse among Women Having Unmet Need for Contraception in Developing Countries Reasons for Contraceptive Nonuse among Women Having Unmet Need for Contraception in Developing Countries For decades, the of unmet need for the contr 2017;45(2):151-169.

15. Cochran WG. Sampling Techniques. 3rd ed. Hoboken: Wiley; 1977.

16. Faabar A. Factors influencing postpartum contrceptive use in the Jirapa District. Legon: University of Ghana; 2014.

17. World Health Organization. WHO Recommendations on Antenatal care for positive pregnancy experience. WHO Recomm Antenatal care Posit pregnancy Exp. 2016;152 Available from: http://apps.who.int/iris/bitstream/1 0665/250796/1/9789241549912-eng.pdf.

18. World Health Organization. WHO recommendations on postnatal care of the mother and newborn. World heal organ; 2013. p. 1-72. Available from: http://apps.who.int/iris/bitstream/10665/97603/1/9789241506649_eng.pdf

19. Asgharpour M, Villarreal S, Schummers L, Hutcheon J, Shaw D, Norman WV. Inter-pregnancy interval and pregnancy outcomes among women with delayed childbearing: protocol for a systematic review. Syst Rev. 2017;6(1):75 Available from: http://systematicreviewsjournal.biomedcentral.com/articles/1 0.1186/s13643-017-0464-0.

20. Dim CC, Ugwu EO, lloghalu El. Duration and determinants of inter-birth interval among women in Enugu, South-Eastern Nigeria. J Obstet Gynaecol (Lahore). 2013;33(2):175-9. https://doi.org/10.3109/01443615.2012.747494.

21. Rodrigues T, Barros H. Short interpregnancy interval and risk of spontaneous preterm delivery. Eur J Obstet Gynecol Reprod Biol. 2008;136(2):184-8.

22. Stover J, Ross J. How increased contraceptive use has reduced maternal mortality. Matern Child Health J. 2010;14(5):687-95.

23. Van Eijsden M, Smits L, Van der Wal M, Bonsel G. Association between short interpregnancy intervals and term birth; 2008. p. 147-53.

24. Wendt A, Gibbs CM, Peters S, Hogue CJ. Impact of increasing interpregnancy interval on maternal and infant health. Paediatr Perinat Epidemiol. 2012;26(Suppl 1):239-58.

25. Abera Y, Mengesha ZB, Tessema GA. Postpartum contraceptive use in Gondar town, Northwest Ethiopia: a community based cross-sectional study. BMC Womens Health. 2015;15(1):19. https://doi.org/10.1186/s12905-015-0178-1.

26. Jalang' OR, Thuita F, Barasa SO, Njoroge P. Determinants of contraceptive use among postpartum women in a county hospital in rural Kenya. BMC Public Health. 2017;17(1):1-8.

27. Pasha O, Goudar SS, Patel A, Garces A, Esamai F, Chomba E, et al. Postpartum contraceptive use and unmet need for family planning in five low-income countries. Reprod Health. 2015;12(S2):S11. https://doi.org/10. 1186/1742-4755-12-S2-S11.

28. World Health Organization. Family planning: a global handbook for providers: evidence-based guidance developed through worldwide collaboration. World Health Organization; 2011. p. 59-81. Available from: https:/apps.who.int/iris/handle/10665/44028.

29. White K, Teal S, Potter J. Contraception after delivery and short interpregnancy intervals among women in the United States. Obstet Gynecol. 2015;125(6):1471-7.

30. Achyut P, Mishra A, Montana L, Sengupta R, Calhoun LM, Nanda P. Integration of family planning with maternal health services: an opportunity to increase postpartum modern contraceptive use in urban Uttar Pradesh, India. J Fam Plan Reprod Heal Care. 2016;42(2):107-15.

31. Gebremedhin AY, Kebede Y, Gelagay AA, Habitu YA. Family planning use and its associated factors among women in the extended postpartum period in Addis Ababa, Ethiopia. Contracept Reprod Med. 2018;3(1):1. https://doi.org/10.1186/s40834-017-0054-5

32. Abraha TH, Teferra AS, Gelagay AA. Postpartum modern contraceptive use in northern Ethiopia: prevalence and associated factors. Epidemiol Health. 2017;39:e2017012. https://doi.org/10.4178/epih.e2017012.

33. Borda MR, Winfrey W, McKaig C. Return to sexual activity and modern family planning use in the extended postpartum period: an analysis of findings from seventeen countries. Afr J Reprod Health. 2010;14(4):72-9 Available from: http://www.ncbi.nlm.nih.gov/pubmed/21812200.

34. Borda M, Winfrey W. Postpartum fertility and contraception: an analysis of findings from 17 countries; 2010.
35. Bouchard T, Febring R, Schneider M. Efficacy of a new postpartum transition protocol for avoiding pregnancy. J Am Board Fam Med. 2013:35-44.

36. Bwazi C, Maluwa A, Chimwaza A, Pindani M. Utilization of postpartum family planning services between six and twelve months of delivery at Ntchisi District hospital, Malawi. Health (Irvine Calif). 2014;06(14):1724-37. https://doi.org/10.4236/health.2014.614205.

37. Hameed W, Azmat SK, Ali M, Sheikh Ml, Abbas G, Temmerman M, et al. Women's empowerment and contraceptive use: the role of independent versus couples' decision-making, from a lower middle income country perspective. PLoS One. 2014;9(8):e104633.

38. Barber SL. Family planning advice and postpartum contraceptive use among low-income women in Mexico. Int Fam Plan Perspect. 2007;33(1):6-12.

39. Eluwa Gl, Atamewalen R, Odogwu K, Ahonsi B. Success providing postpartum intrauterine devices in private-sector health care facilities in Nigeria: factors associated with uptake. Glob Heal Sci Pract. 2016;4(2):276-83.

40. Hernandez LE, Sappenfield WM, Goodman D, Pooler J. Is effective contraceptive use conceived prenatally in Florida? The association between prenatal contraceptive counseling and postpartum contraceptive use. Matern Child Health J. 2012;16(2):423-9.

41. Mengesha ZB, Worku AG, Feleke SA. Contraceptive adoption in the extended postpartum period is low in Northwest Ethiopia. BMC Pregnancy Childbirth. 2015;15(1):160. https://doi.org/10.1186/s12884-015-0598-9.

\section{Publisher's Note}

Springer Nature remains neutral with regard to jurisdictional claims in published maps and institutional affiliations.
Ready to submit your research? Choose BMC and benefit from:

- fast, convenient online submission

- thorough peer review by experienced researchers in your field

- rapid publication on acceptance

- support for research data, including large and complex data types

- gold Open Access which fosters wider collaboration and increased citations

- maximum visibility for your research: over $100 \mathrm{M}$ website views per year

At BMC, research is always in progress.

Learn more biomedcentral.com/submissions 